\title{
Evaluation of Operational Wave Forecasts for the Northeastern Coast of Taiwan
}

\author{
Beng-Chun Lee ${ }^{1}$, Hwa Chien ${ }^{2, *}$, Hao-Yuan Cheng ${ }^{2}$, and Ming-Da Chiou ${ }^{3}$ \\ ${ }^{I}$ Department of Environmental and Hazards-Resistance Design, Huafan University, Taipei 223, Taiwan, ROC \\ ${ }^{2}$ Institute of Hydrological and Oceanic Sciences, National Central University, Jhongli 320, Taiwan, ROC \\ ${ }^{3}$ Institute of Hydraulic and Ocean Engineering, National Cheng Kung University, Tainan 701, Taiwan, ROC
}

Received 22 September 2008, accepted 3 June 2009

\begin{abstract}
An operational regional wave forecasting system was established to fulfill the demands of maritime engineering applications on the northeastern coast of Taiwan. This Mixed system consisted of a nested SWAN numerical wave model and experienced marine meteorologists who were sent to the construction site as the in situ predictors to validate output from the numerical model so as to improve the forecasting accuracy.

This paper will offer an evaluation of this regional wave forecasting system. Records of hourly forecasts from June to October 2004 obtained by direct numerical model and the in situ predictors' modifications are comprehensively compared. First, the nested SWAN is verified with the observational data. The Alves and Banner's (2003) wave energy dissipation term is adopted for better wave period simulation. The error analysis is then carried out to discriminate the performances of the system to the direct numerical model. It is found that the in situ predictors provided invaluable modifications which reduced the root mean square error by $30 \%$ to the deviated model outputs as well as the quality of the forecasted wind fields used to drive the wave model played key role to the wave prediction. About $20 \%$ of the errors of +3 days wave predictions were incurred by the uncertainties of wind fields. As the miss-predicted trajectory of typhoon centers exceeding $90 \mathrm{~km}$, the wave predictions would not be valid, and the benefits from in situ predictors became marginal. Finally, land and sea breezes are important factors in regional wave forecasts for engineering applications as both can induce diurnal wave heights oscillations, which is not destructive, but crucial to the quality of marine engineering. As the scale of the land/sea breeze is not resolved in the operational forecasted wind fields issued by Central Weather Bureau. Currently, the implementation of in situ predictors is necessary.
\end{abstract}

Key words: Regional wave forecast, Man-machine mix system, SWAN wave model

Citation: Lee, B. C., H. Chien, H. Y. Cheng, and M. D. Chiou, 2010: Evaluation of operational wave forecasts for the northeastern coast of Taiwan. Terr. Atmos. Ocean. Sci., 21, 195-210, doi: 10.3319/TAO.2009.06.03.02(IWNOP)

\section{INTRODUCTION}

A nuclear power plant cooling-water discharge tunnel (8 $\mathrm{m}$ diameter) was constructed under the sea-bed in the Longmen area of Taiwan (2003 to 2005). Considering the promotion of safety of engineering activities as well as better construction management efficiency in maritime engineering planning and decision making, the forecast of oceanic environments was essential. Among the physical oceanographical factors, wave is the most dominating factor for operation safety and performance (Cox and Cardone

\footnotetext{
* Corresponding author

E-mail:hchien@ncu.edu.tw
}

2002). Requested operations on the offshore platforms and vessels could be performed as the significant wave height less than $1.0 \mathrm{~m}$. When the significant wave heights increase to $1.5 \mathrm{~m}$, alerts of sea severity will be issued and activities that required precision operations have to be postponed. With the significant wave height exceeding $1.5 \mathrm{~m}$, warnings will be broadcasted to call off the offshore construction; vessels therefore must be moored or birthed in harbors.

The significant wave heights of 1.0 and $1.5 \mathrm{~m}$ are the thresholds. An $\mathrm{O}\left(10^{-1}\right) \mathrm{m}$ scale difference of significant wave height prediction would lead to decisions of conctradiction. High risks will be arise if the wave heights were 
miss-predicted. Moreover, as requested by maritime and coastal engineering operators, hourly wave forecasts for the succeeding one-day, three-days and seven-days have to be provided before 0630,1030 , and 1600 local time, respectively.

The operational wave forecasts around Taiwan waters were disseminated to the public routinely by the Central Weather Bureau, Taiwan (CWB) via television and internet websites for fishery and navigation orientation. Daily predictions of wave heights were tabulated with the Beaufort scale. The resolution of predicted wave heights, temporal variation and the issue frequency certainly did not satisfy the needs in the maritime engineering applications. Therefore, an operational high resolution/accuracy wave forecasting system for a specific site was necessary. In present study, the establishment of the regional wave forecasting system and its assessment are described and discussed.

In order to ensure the capability of obtaining valid and accurate wave predictions with this regional wave forecasting system, the strategies were twofold. One was to employ a sophisticated numerical model and moreover, experienced marine meteorologists as the in situ predictors sent to justify and modify the model outputs. This formed the Mixed prediction system. The aims of present study are to evaluate the performance of this system and also the role of the in situ predictors, especially to investigate how the in situ predictors benefit the performance of the system. A brief description of the setup of a regional wave forecasting system is made in the second section. Analysis and comparisons of error statistics that obtained from both the outputs of the numerical models as well as the products of in situ predictors are carried out.

\section{SETUP OF REGIONAL WAVE FORECASTING SYSTEM}

The regional forecasting system consisted of two parts, i.e., the nested numerical wave model and the wave predictors. The wave predictors were responsible for the judgment, assessment and modification of the output of numerical model using real-time wave and meteorological data.

In the operational mode, one-, three-, and seven-day wave forecasts should be issued at 0630, 1030, and 1630 local time, daily. In order to assist the in situ predictors making the judgment and modification of the model outputs with ease and efficiency, a web-based informatic system was developed. This information system was automatically fed with the model outputs, which were calculated in a university lab, in netCDF format right after each run $(0000$ and 1200 UTC, twice per day). The coded data were then transmitted with data from other sources, including surface wind field predictions, satellite images and near real-time observed marine-meteorological data, as email attachment, which could then be received by the on-site predictors' PDA or laptop through wired or wire-less internet. The informatic system on the predictors' side then decoded the data and demonstrated them in tabular and GIS graphical format. Displays of the predicted waves included significant wave heights, directions, periods and directional spectra taken from the nearest model grid point to the construction site. The in situ predictor could hence obtain the overall information from various sources of independent institutes. The system was the primary tool for the in situ predictor to modify the model outputs.

\subsection{Configuration of Wave Model}

A basin/regional scale one-way nested wave model was setup. The SWAN model was adopted for both the basin scale model and the regional model. The basin scale model ran twice daily at $00 \mathrm{Z}$ and $12 \mathrm{Z}$ and provided the wave forecast as the input boundary of regional scale model. This basin scale model produced forecasts for the next 7 days twice each day. The grid area of the basin scale model covered $0-40^{\circ} \mathrm{N}$ degree latitude and $100-140^{\circ} \mathrm{E}$ degree longitude, namely the north-western Pacific and Asia Shelf Seas. It ran on a 0.5 degree by 0.5 degree latitude/longitude grid and provided the directional wave action density at 13 grid points, which were offered as the regional model boundary condition. Feeding the wave model with the predicted wind fields, the output of the first 24 hours from the basin model was regarded as the spin up processes and was not used. The regional model computational domain covers $24.5-26.5^{\circ} \mathrm{N}$, $121.5-123.5^{\circ} \mathrm{E}$ in an area of approximately $48000 \mathrm{~km}^{2}$ as illustrated in Fig. 1. The spatial resolution was $2 \mathrm{~km}$, and the discrete spectrum consists of 36 directions $\left(\Delta \theta=10^{\circ}\right)$ and 34 frequencies (from 0.042 to $1 \mathrm{~Hz}$ with a logarithmic increment).

The surface wind fields that used to drive the wave model were obtained from the National Centers for Environmental Prediction, USA (NCEP) and Central Weather Bureau, Taiwan (CWB). The meso-scale CWB nonhydrostatic limited area forecast system (NFS) provided high resolution $(15 \mathrm{~km})$ forecasting surface wind fields around Taiwan waters about 40 minutes after $00 \mathrm{Z}$ and $12 \mathrm{Z}$. The predictions extended into the medium range ( 168 hours) and their girded surface wind fields were available in near realtime in operational mode. Evaluation of these forecasts (e.g., Liou 1997) indicated that they predict very well beyond 2 days, and contaminations of system errors increase after 5 days. As the NCEP Global Forecast System (GFS) at present does not adequately resolve tropical cyclones, and the CWB surface wind field products did not adequately cover the basin computational domain, in this study the products of CWB NFS were used to drive both the basin and regional wave model. For the areas in the basin model computational domain that could not be covered by the CWB NFS wind fields, the NCEP GFS wind fields were used. 


\subsection{The SWAN Wave Model}

The SWAN model is the third generation phase average spectral model. Based on the wave action balancing equations in Eq. (1), the SWAN is capable of simulating wave evolution, frequency downshift, shoaling and refraction in the deep and nearshore water (Booij et al. 1996; Holthuijsen et al. 1997, 1999).

$$
\frac{\partial N(\vec{k}, \vec{x}, t)}{\partial t}+\nabla \cdot \vec{c} N(\vec{k}, \vec{x}, t)=S(\vec{k}, \vec{x}, t)
$$

In Eq. (1), $\vec{k}$ is the wavenumber vector, $N$ is the wave action spectral density function, $\vec{c}$ is the advection velocities in spectral and physical spaces, and $S$ describes nonconservative processes (source/sink terms). This equation states that the temporal and spatial evolution of the wave directional spectra is forced by the energy source and sinks terms. These terms include the $S_{i n}, S_{n l 4}, S_{d s}, S_{n l 3}, S_{b r}$, and $S_{b f}$ representing the wind energy input, quadruplet nonlinear wave-wave interaction, dissipation due to whitecaps, the wave shoaling, limited depth breaking and bottom friction respectively. It is noted that $S_{i n}, S_{n l 4}$, and $S_{d s}$ predominate, especially in the deep ocean. Among the source and sink terms, the wave white-capping dissipation mechanism is the crucial and least understood one, since spectral wave energy dissipation has never been measured (Rogers et al. 2003; Westhuysen et al. 2007). The strategy for improving the $S_{d s}$ formulation was to assume that the other two main deep water source terms (i.e., $S_{i n}$, wind input and $S_{n l 4}$ quadruplet wave-wave nonlinear interactions) are accurate and then adjust the dissipation by generate a function of combination of the characteristics of the individual spectral component and the current sea state to achieve the desired growth rate or equilibrium state (Rogers et al. 2003).

\subsection{The White-Capping Dissipation Term}

A number of dissipation terms had been proposed to improve the simulation performance of SWAN (Banner et al. 2000, 2002; Young and Babanin 2006). Donelan and Yuan (1994) distinguished these dissipations terms into three categories, i.e., the whitecap models, probability models and quasi-saturated models. The $S_{d s}$ in the SWAN was proposed by Komen et. al. (1984). It is categorized as a whitecap model. The tuning of this term was also performed by Komen et al. (1984), who conducted numerical experiments with different white-capping term coefficients to closed the energy balance in deep water and match the bulk parameters of the Pierson-Moskowitz spectrum. Komen's white-capping dissipation was rewritten by Donelan and Yuan (1994) as :

$$
\begin{aligned}
& S_{d s}(k, \theta)=\gamma_{d s} \cdot S(k, \theta) \\
& \gamma_{d s}=-C_{d s} \cdot\left(\frac{\bar{s}}{\bar{S}_{P M}}\right)^{m} \cdot \frac{k}{\bar{k}} \cdot \bar{\sigma} \\
& \bar{s}=\bar{k} \sqrt{E_{\text {total }}} \\
& \bar{\sigma}=\left[E_{\text {tot }}^{-1} \int_{0}^{2 \pi} \int_{0}^{\infty} \frac{1}{\sigma} S(\sigma, \theta) d \sigma d \theta\right]^{-1} \\
& \bar{k}=\left[E_{\text {tot }}^{-1} \int_{0}^{2 \pi} \int_{0}^{\infty} \frac{1}{\sqrt{k}} S(\sigma, \theta) d \sigma d \theta\right]^{-2} \\
& E_{\text {tot }}=\int_{0}^{2 \pi} \int_{0}^{\infty} S(\sigma, \theta) d \sigma d \theta
\end{aligned}
$$

Where $C_{d s}$ is the drag coefficient, $C_{d s}=2.36 E-5, \bar{s}$ is the mean wave steepness, $\bar{s}_{P M}$ is the wave steepness estimated from Pierson-Moskowitz spectrum, $\bar{s}_{P M}=5.49 E-2, m=4$. Janssen $(1989,1991)$ proposed a revised version,

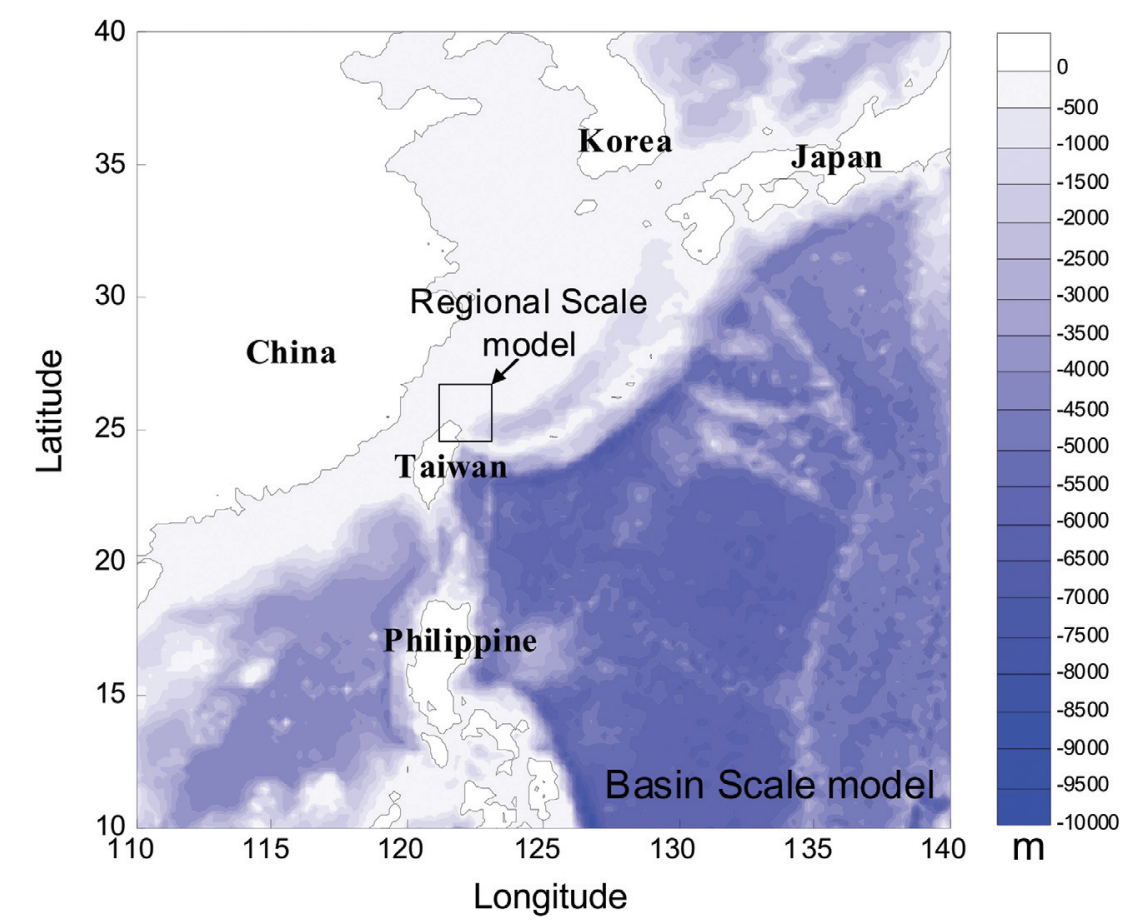

Fig. 1. The computational domain of the basin scale and regional scale SWAN model. 
$\gamma_{d s}=-C_{d s} \cdot\left(\frac{\bar{s}}{\bar{s}_{P M}}\right)^{m} \cdot\left(1-\delta+\delta \frac{k}{\bar{k}}\right) \cdot \frac{k}{\bar{k}} \cdot \bar{\sigma}$

Where $\delta$ is a tunable parameter, $\delta=0.5$. It is noted that when $\delta=0$, Eq. (5) is consistent with Komen's formula. It should be noted here that, this formula is based on the assumption that the dissipation is dependent on the overall wave steepness relative to an equilibrium steepness $\bar{s} / \bar{s}_{P M}$.

More recently, it has been shown that waves do not necessarily have to reach the steepness threshold to break. In addition, once they are breaking, they do not stop at the Stokes limiting steepness but may keep loosing energy until their steepness is well below the mean wave steepness (Liu and Babanin 2004). Based on the wave breaking scenario, Alves and Banner (2003) proposed another dissipation formula,

$\gamma_{d s}=-C_{d s} \cdot\left[\frac{B(k)}{B_{r}}\right]^{p / 2}\left(E_{t o t} k_{p}^{2}\right)^{m}\left(\frac{k}{\bar{k}}\right)^{n} \cdot \omega$

$B(k)=k^{3} S(k)$

$S(k)=\int_{-\pi}^{\pi} S(k, \theta) d \theta$

$\begin{cases}p=\frac{p_{0}}{2}+\frac{p_{0}}{2} \tan h\left\langle 10\left\{\left[\frac{B(k)}{B_{r}}\right]^{1 / 2}-1\right\}\right\rangle, & B(k)>B_{r} \\ p=0, & B(k)<B_{r}\end{cases}$

$B(k)$ is referred to the saturation spectrum. This formula regarded dissipation as essentially local in wave number space and consequently offered a way to resolve the spurious behavior of SWAN under combined swell-sea conditions (Westhuysen et al. 2007). As this formula is highly sensitive to the level of saturation threshold, $B_{r}$, where validation of the parameters is needed.

In present study, the SWAN original setting using Komen's (1984) and Alves and Banner's (2003) formulations of wave white-capping dissipation were tested and compared. The parameters from the Alves and Banner (2003) terms were calibrated accordingly.

Two initial parameter sets, denoted as C-I and C-II, were used for comparison.

\begin{tabular}{lll}
\hline $\begin{array}{l}\text { Parameters } \\
\text { setting }\end{array}$ & $S_{d s}$ & Value of the constants in $S_{d s}$ \\
\hline C-I & Alves and & $\begin{array}{l}C_{d s}=5 \times 10^{-4}, P=4, m=0.3, n=1, \\
\text { Banner }\end{array}$ \\
$\begin{array}{l}B_{r}=2 \times 10^{-3} \\
\text { C-II }\end{array}$ & Komen & $\begin{array}{l}C_{d s}=2.36 \times 10^{-6}, S_{P M}=5.49 \times 10^{-2}, \\
m=4\end{array}$ \\
\hline
\end{tabular}

\subsection{In Situ Predictor}

The in situ predictors modified the direct numerical model output mainly according to the historical record and real-time wave measurements. First, in order to determine the trend of wave evolution, they searched the weather map histories for the weather system patterns or events that were similar to the ongoing ones. Second, they retrieved the corresponding observation data from the data achieve. Third, based on the model output time series, they modified the magnitude of wave heights and periods according to the historical data, and finally, fine tuned the results by the realtime wave observations and the monitored air-sea heat flux, whitecap coverage, cloud type they could observe from the construction site. These steps are similar to the artificial neural network method; however, the first and last steps are difficult to be coded into computer programs. In the next section, the roles of in situ predictors are discussed.

\section{NUMERICAL MODEL VALIDATION}

In this section, the evaluation of the system performance is carried out with respect to the typhoon condition and monsoon condition.

\subsection{Observation Data}

The CWB and the Water Resource Agency, Taiwan (WRA), operate networks of moored directional buoys along the coastal and shelf regions of Taiwan. The Longdong buoy, which was selected for validation of the forecasting system, located in the computational domain of the regional wave models. The disc type Longdong buoy was deployed in the water depth approximately $30 \mathrm{~m}$. Dual wind sensors were mounted $3 \mathrm{~m}$ above the sea level. Buoy hull motions, i.e., the heave acceleration, pitch and roll, were recorded in $2 \mathrm{~Hz}$ sampling rate. Significant wave heights and mean periods were obtained from the displacement spectra, which were transformed from vertical acceleration spectra linearly. The interval of observation was two hours in normal weather condition and will be shorten to one hour when the typhoon alerts were issued. These data, together with other meteorological factors were transmitted to the data center via GSM system in near real-time.

The construction company also deployed a bottom mounted acoustic wave probe and current profiler (Nortek AWAC) at the construction site where the averaged water depth was $9 \mathrm{~m}$. However due to the intensive sedimentation activity and morphodynamic change in this region, stable and continuous working conditions could not be obtained. Very limited piecewise data was recorded. Therefore, only the data from the data buoy could be used for the model validation and evaluation. It should be noted that due to the geographical conditions in the locations of the buoy station and 
the construction site, the wave climates might vary. Figure 2 illustrates the locations of the AWAC and the buoy. The location of Longdong buoy was $25^{\circ} 5.77^{\prime} \mathrm{N}, 121^{\circ} 55.41^{\prime} \mathrm{E}$. The Nortek AWAC station was $6 \mathrm{~km}$ apart located at $25^{\circ} 2.57^{\prime} \mathrm{N}$, $121^{\circ} 56.25^{\prime} \mathrm{E}$. Figure 3 is the comparison between the observed wind speed to the atmospheric model ouput U10 at the construction site.

To realize the difference of wave climates in these two areas, regression analysis had been carried out using

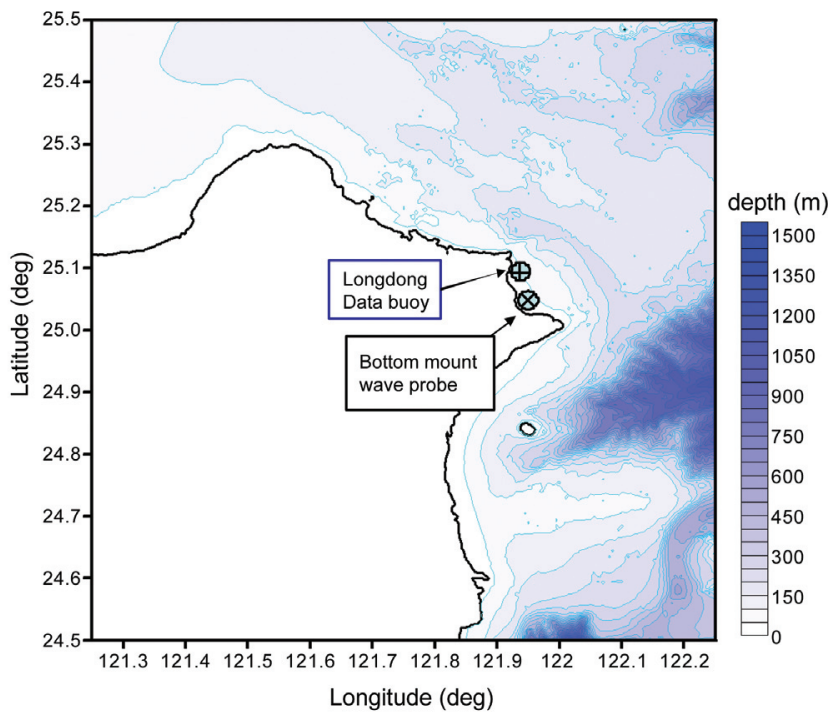

Fig. 2. A close up of the domain of regional scale model and the locations of the in situ wave observation stations. The location of Longdong data buoy was $25^{\circ} 5.77^{\prime} \mathrm{N}, 121^{\circ} 55.41^{\prime} \mathrm{E}$ with a water depth of $30 \mathrm{~m}$; The bottom mounted Nortek AWAC station was located at $25^{\circ} 2.57^{\prime} \mathrm{N}, 121^{\circ} 56.25^{\prime} \mathrm{E}$ with a water depth of $9 \mathrm{~m}$.

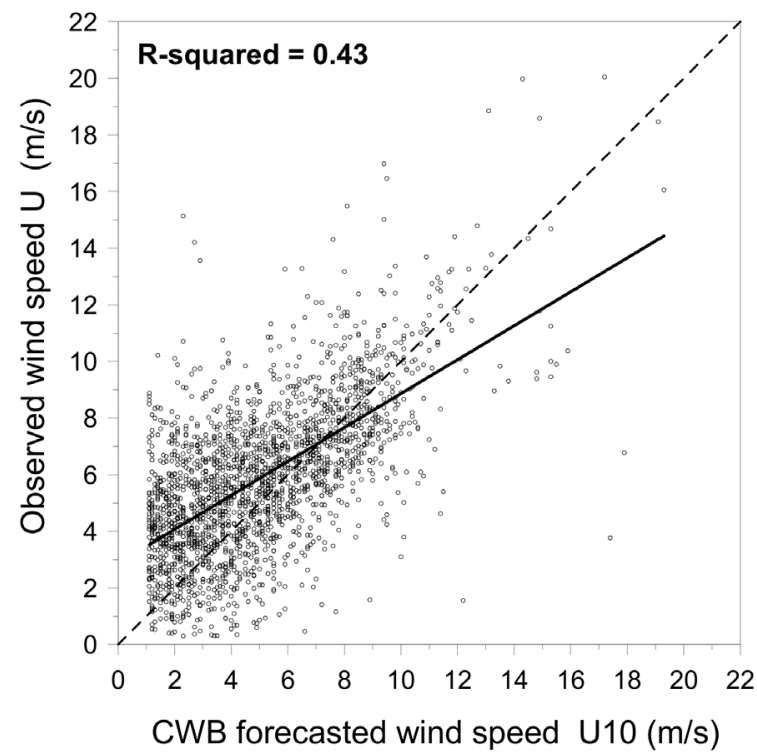

Fig. 3. A comparison between observed wind speed and the forecasted U10 from the CWB atmospheric model outputs at the construction site. Dots denote hourly data from June to October 2004. the data from data buoy and the bottom mount wave probe. Figure 4 demonstrates the correlation of the observed significant wave height (Hs) measured from the Longmen station and Longdong buoy. The data were divided into three sub-groups according to the construction thresholds 1.0 and 1.5 m.of wave heights. For calm seas ( $\mathrm{Hs}<1 \mathrm{~m}$ ), the wave heights in the construction area were overall about $40 \%$ smaller than that measured from the data buoy. With the increase of wave height from 1.0 to $1.5 \mathrm{~m}$, the ratio between the Longdong measurement and Longmen measurement decreased and approached to 1 with an offset of $0.65 \mathrm{~m}$. The Longdong observations were used to infer the wave condition in the construction site for the decision making of engineering applications. For larger and longer waves, the correlation coefficient reduced, data trended to be scattered. It has to be noted that the in situ predictor gave wave predictions of the construction area, which might not be exactly in the same sea state as where the Longdong buoy was located.

\subsection{Error Indexes}

To evaluate the performance of the numerical models and the Mixed system, three statistical parameters were used. i.e., the Bias, Root Mean Square Error and Scatter Index. The definitions of the parameters are described as follow.

If $F$ is the system forecast value, $O$ the observation, $\bar{F}=\frac{1}{N} \sum F$ is the mean of forecasts, $\bar{O}=\frac{1}{N} \sum O$ is the mean of observations, $\Delta F=(F-O)$ is the difference between the forecast and observations, and $\mathrm{N}$ the number of observation data set, then definitions of bias (BIAS), root mean square error (RMSE) and scatter index (SI) are defined below,

$\mathrm{BIAS}=\frac{1}{N} \sum_{i=1}^{N} \Delta F_{i}=\bar{F}-\bar{O}$

$\operatorname{RMSE}=\frac{1}{N} \sqrt{\sum_{i=1}^{N}\left(\Delta F_{i}^{2}\right)}$

$\mathrm{SI}=\sqrt{\frac{\sum_{i=1}^{N}\left(F_{i}-O_{i}\right)^{2}}{N \cdot \bar{O}}}$

The bias is used to indicate the quantity of deviation of the forecasting system. By taking the average of bias over the period, the under-estimation or over-estimation of the system could be identified. The RMSE, which is of positive values, demonstrate the accuracy and magnitude of the error of the forecasting system. Reliability and risk could thus be assessed for being as the references to the decision maker. 

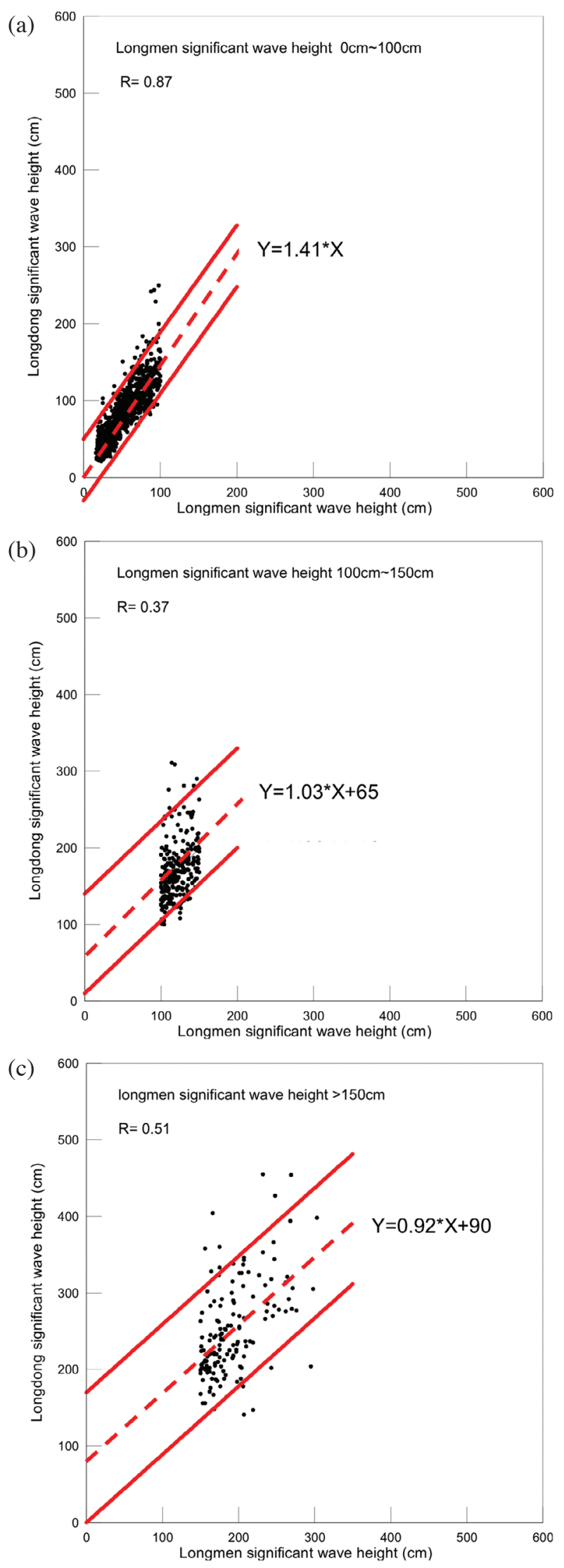

Fig. 4. Correlations of observed waves from the Longmen acoustic AWAC and Longdong buoy. (a) Longmen $\mathrm{Hs}<100 \mathrm{~cm}$; (b) $100 \mathrm{~cm}<$ Longmen $\mathrm{Hs}<150 \mathrm{~cm}$; (c) Longmen $\mathrm{Hs}>150 \mathrm{~cm}$.
The SI, which is dimensionless, indicates the error percentage of the system. The above three error parameters are used to evaluate of the system.

\subsection{TheTuning of White-Capping Dissipation Term}

The maritime construction was not able to be implemented during the winter season due to the prevailing winter monsoon waves. The data produced by the wave forecast system in operational mode were only avalible from 2004/06/16 to 2004/10/26. During this period, there were 11 typhoons/TDs that brought direct or indirect impacts to the construction site. The weather systems are listed in Table 1. Among those, seven typhoons were warned by CWB, three (Mindulle, Aere and Haima) had landfalls to Taiwan. These typhoon waves occupied $30 \%$ of the period; whereas $70 \%$ was dominated by the south-western summer monsoon. Due to the terrestrial shading effects and limited fetch, the summer monsoon waves at the construction site were relatively clam. According to the Longdong buoy observations, $51 \%$ of the significant wave heights during this period were lower than $1.0 \mathrm{~m}$.

In order to investigate the performance of wave numerical model, the effects owing to the uncertainties from forecasted wind field needed to be reduced. Herein, the CWB re-analysis surface wind fields, which were data assimilated, were used to drive the wave field. These wind fields were downscaled using linear interpolation to meet the needs of wave model. Figures 5 and 6 demonstrate the significant wave heights and periods comparisons between observations to the model outputs. The outputs of the model using Komen's formula with C-I setting are denoted as a dashed line; whilst Alves and Banner's formula with C-II setting are denoted as a solid line. From the wave height comparison, the variation trend estimated by both numerical models of SWAN_default and SWAN_A\&B agree with the observations. But both model setups under-estimate the maximum wave heights of typhoon waves during the Typhoon passage. Figure 7 is an example that illustrates the differences of the wave spectral shape between the observation and model simulations using C-I and C-II settings at 2004/07/02 0800Z during typhoon Mindulle. The blue solid line, which represents the results from C-I setting, is closer to the observation as denoted by the dotted-black line. The C-II setting gave less peaky spectral shape and skewed to higher frequency band and led to less wave period estimation. The first moment of the C-II spectrum was almost the identical to the C-I, resulting equivalent estimation of significant wave heights. The timing of the arrival of maximum waves of Typhoon Mindulle (I) Haima (V) and Meari (VII) were not well estimated. It should also be noted that the model did not reflect detailed variation during a cold front passage $(09 / 21 \sim 09 / 23)$ as both model setups miss-predicted the timing of the occurrence of peak wave heights. 
Table 1. List of typhoons and weather systems that struck the construction site.

\begin{tabular}{|c|c|c|c|c|c|c|}
\hline No. & Mark & $\begin{array}{c}\text { Typhoon/ } \\
\text { Weather system }\end{array}$ & $\begin{array}{c}\text { Period of } \\
\text { approaching to } \\
\text { Taiwan }\end{array}$ & Landfall on Taiwan & CWB warning & $\begin{array}{c}\text { Saffir-Simpson } \\
\text { Category of } \\
\text { maximum intensity }\end{array}$ \\
\hline 1 & A & CONSON (200404) & 06/07 06/09 & & 0 & 1 \\
\hline 2 & $\mathrm{~B}$ & DAINMU (200406) & $06 / 19 \sim 06 / 20$ & & & 3 \\
\hline 3 & I & MINDULLE (200407) & $06 / 28 \sim 07 / 03$ & 0 & 0 & 2 \\
\hline 4 & II & KOMPASU (200409) & $07 / 14 \sim 07 / 15$ & & 0 & 1 \\
\hline 5 & III & RANANIM (200413) & $08 / 10 \sim 08 / 13$ & & 0 & 1 \\
\hline 6 & $\mathrm{C}$ & MEGI (200415) & $08 / 17 \sim 08 / 18$ & & & 1 \\
\hline 7 & IV & AERE (200417) & $08 / 23 \sim 08 / 26$ & 0 & 0 & 1 \\
\hline 8 & $\mathrm{D}$ & CHABA (200416) & $08 / 30 \sim 09 / 01$ & & & 3 \\
\hline 9 & $\mathrm{E}$ & SONGDA (200418) & $09 / 05 \sim 09 / 07$ & & & 2 \\
\hline 10 & $\mathrm{~V}$ & HAIMA (200420) & $09 / 11 \sim 09 / 13$ & 0 & 0 & 1 \\
\hline 11 & VI & Winter Cold Front & $09 / 21 \sim 09 / 23$ & & & \\
\hline 12 & VII & MEARI (200421) & $09 / 26 \sim 09 / 27$ & & 0 & 2 \\
\hline
\end{tabular}
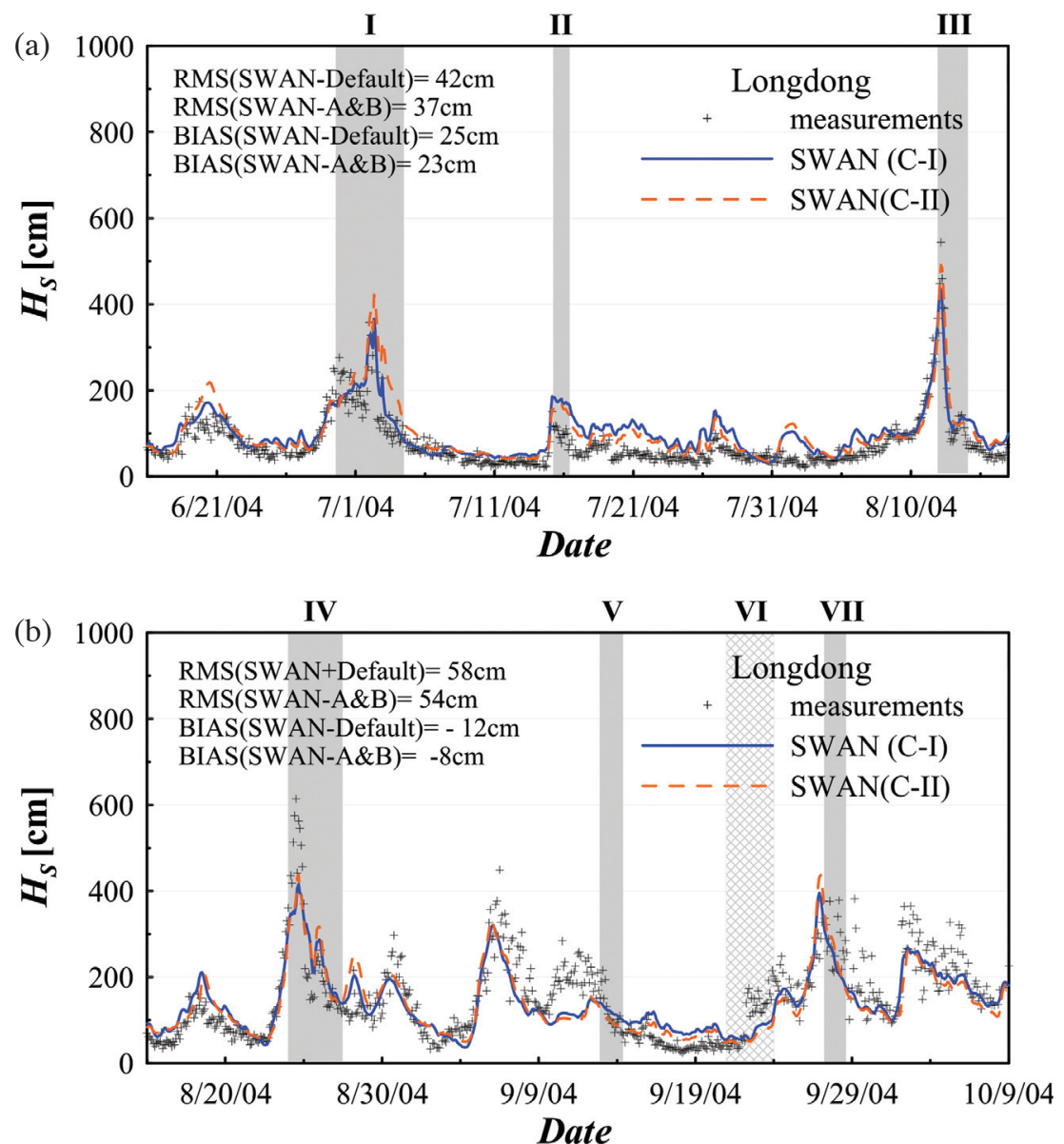

Fig. 5. Comparisons of observational significant wave heights from the Longdong buoy to the SWAN model output. The re-analysis wind fields were used to drive the wave model. The shaded areas denote the durations affected by typhoons, TD or cold front issued by CWB. (a) Comparisons from $2004 / 06 / 16$ to $2004 / 08 / 14$; (b) comparisons from $2004 / 08 / 15$ to $2004 / 10 / 09$. 

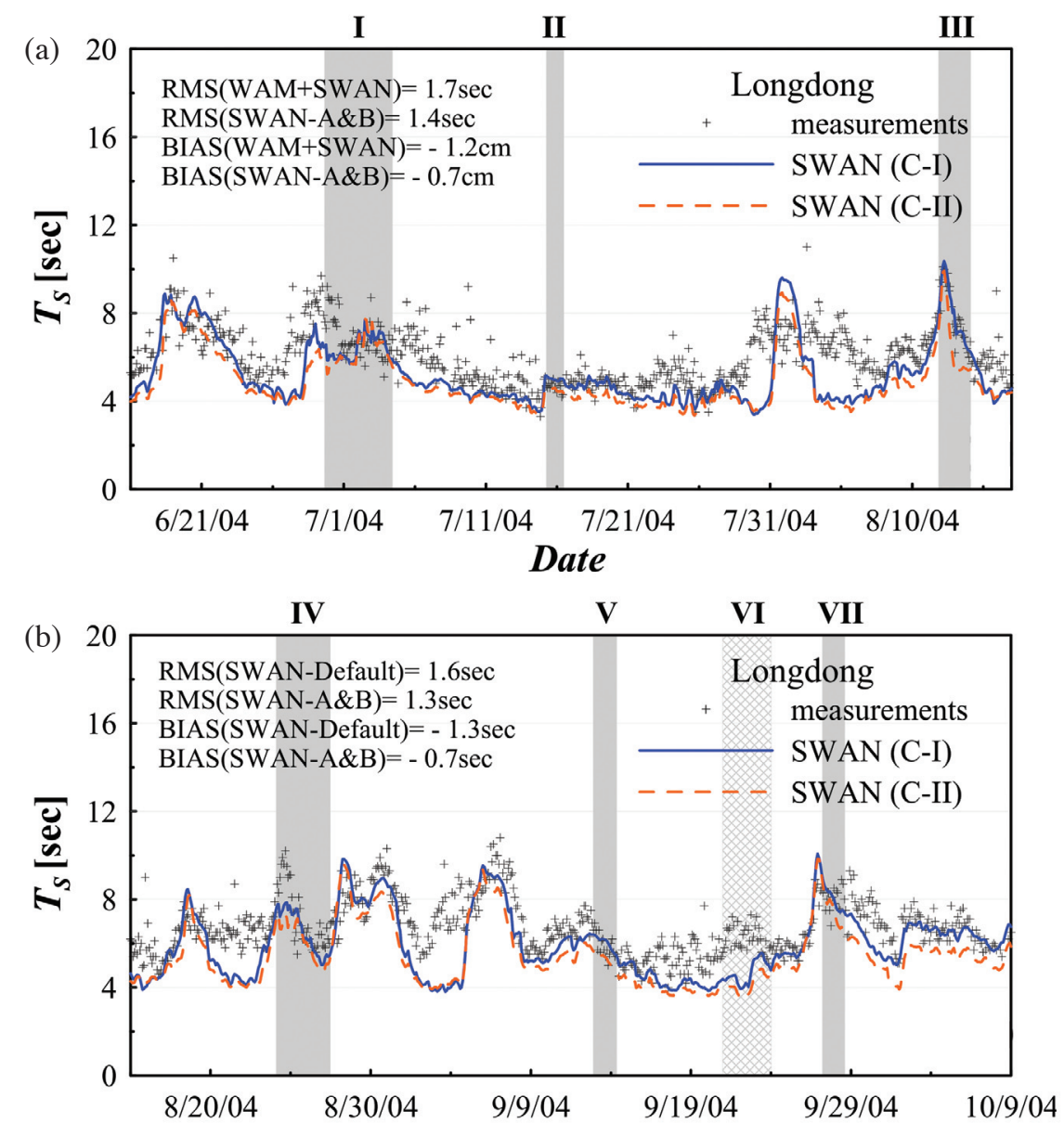

Fig. 6. Comparisons of observational significant wave periods from the Longdong buoy to the SWAN model output. The re-analysis wind fields were used to drive the wave model. The shaded areas denote the duration affected by typhoons, TD or cold front issued by CWB. (a) Comparisons from 2004/06/16 to 2004/08/14; (b) comparisons from 2004/08/15 to 2004/10/09.

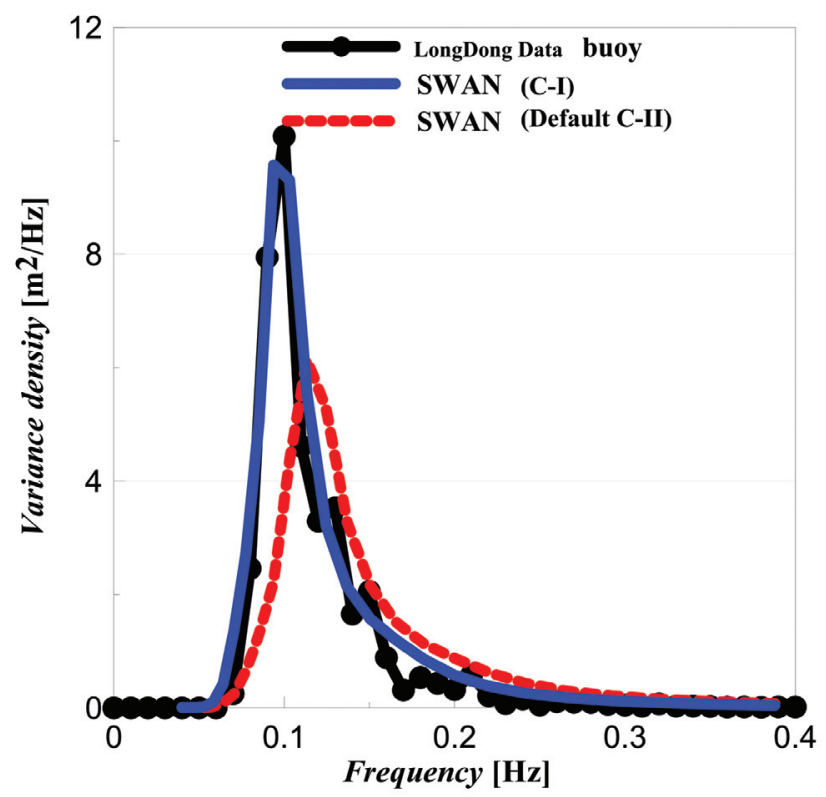

Fig. 7. Comparisons of the wave spectra, estimated using Komen and Alves and Banner formulas at 2004/07/02 0000Z during typhoon Mindulle.
When there were no dominating weather systems such as fronts or typhoon/TDs in the vicinity, from 07/21 07/28 and 09/14 09/21, observation of significant wave heights ranged from $0.4 \mathrm{~m}$ to $0.9 \mathrm{~m}$, the model outputs were about $40 \% \sim 100 \%$ larger than that observed. The forecast errors were around the maximum acceptable value from the viewpoint of maritime engineering. It is found in Figs. 6 and 7, that the SWAN default under-estimated the wave period. From the error index comparisons, it should be stressed that by adopting Alves and Banner's dissipation formula, wave simulation is improved. When adopting the SWAN_A\&B, the overall RMSE of significant wave height was $0.455 \mathrm{~m}$, $1.35 \mathrm{sec}$ for wave periods. The model was $0.13 \mathrm{~m}$ over-predicted the significant wave height, $0.7 \mathrm{sec}$ under-predict the wave period.

\section{WAVE FORECAST AND CASE STUDY}

\subsection{Forecast Reliability}

The offshore construction started from June to Octo- 
ber 2004. Considering that the prevailing winter monsoon waves dominated the sea state at the construction site from autumn to the next spring each year, this period was the only window in the entire year that the offshore construction could be implemented. The typhoons which struct the coast are listed in Table 1. The prediction of the local sea states that were affected by the typhoon waves and the swell generated in the far field was one of the major challenges. In the present section, the hourly predicted data that were produced and issued during this summer were used as the basis for error indexes statistics. As the forecasts were issue daily, these hourly error indexes were averaged over the whole day.

The overall performance of the direct numerical model output (denoted as DNM hereinafter), which was driven by forecasting surface wind fields, and the products issued by in situ predictor (Man Mixed, denoted as MM hereinafter) are compared and discussed. The reliability of the DNM wave height forecast +1 day can be found in Fig. 8. It is the result of the daily variance of the error histogram indexes. The probability distributions of the daily variance of the error indexed are then obtained and illustrated in Figs. 9 and 10. In order to investigate the effects of the uncertainty contamination in the forecasted wind fields, the overall error indexes of model that were driven by re-analysis wind fields, as described in the previous section, and model that driven by forecasted wind fields are compared in Table 2. The RMSE of the DNM using +1 day forecasted wind fields is $0.485 \mathrm{~m}$, which is $0.03 \mathrm{~m}(6.6 \%)$ larger than those driven by the re-analysis wind fields. For the prediction of +3 and +5 days using forecasted wind fields, the RMSE increases to 0.537 and $0.596 \mathrm{~m}$, which are $0.082 \mathrm{~m} \mathrm{(19 \% )}$ and 0.141 $\mathrm{m}(31 \%)$ larger, respectively. For a longer term prediction, a larger uncertainty is included. It is seen from the results that for a +3 days wave height forecast, a $20 \%$ error is induced by the uncertainties of the forecasted wind fields.

On the other hand, the error indexes daily variation of the products by in situ predictors (MM) are illustrated in Figs. 11 and 12. From the statistic values of the data set, it is found that the predictions of +1 day, +3 and +5 days, the MM gave better predictions than DNM. The overall error indexes are reduced in magnitude of the output of MMM. Figure 13 is the scatter plots that demonstrate the performance of MM for wave height and period forecasting using MM. The performance of wave period prediction is still far from satisfactory. In the following sections, the results from DNM and MM are quantitatively compared through statistical analysis and case study.

\subsection{Case Studies}

Due to the fact that there were significant differences between the performance of forecast system in the summer monsoon and typhoons, we first distinguished the typhoon data, as indicated by the shaded area in Figs. 6 to 11 from the whole data set. In our data base, there were about 35 days (approximately 30\% of the whole duration) influenced by typhoons. The rest of the data was regarded as the summer monsoon period. The error indexes of +3 days wave heights predictions from DNM and MM are listed in Table 3. Benefits of the adopting MM can be found that the RMSE of Hs prediction of +3 days of DNM is reduced from 0.51 to $0.35 \mathrm{~m}$ and 1.03 to $0.75 \mathrm{~m}$ (both about $30 \%$ ) for summer monsoon and typhoon data sets respectively. In Table 4, the trend of under-estimation of wave period in the monsoon and in the typhoon could be revealed, and this effect was removed by adopting MM. By employment of in situ predictors, the accuracy of the predictions improve by about $30 \%$ than without them.

From the Fig. 8, spiky values of the error indexes can be identified during some specific typhoons. The 06/19 (Dianmu), 06/28 (Mindulle), 08/10 (Rananin), and 08/23 (Aere) were the top four events of the miss-estimated wave heights according to the BIAS and RMSE for forecast of day +1 as well as day +3 . It should be noted that even a far field typhoon, i.e., Dianmu, which was not warned by CWB, incurred significant wave miss-prediction. Typhoon Dianmu, which was classified as the fifth category, was one of the examples that its intensity and track were both mispredicted in the operational mode. According to the warnings issued on 16 June 2004 by the Joint Typhoon Warning Center (JTWC), Regional Specialized Meteorological Center (RSMC) in Tokyo, Hong Kong Observatory (HKO) and CWB, Taiwan, disagreements occurred among the warning centers on the intensity and trajectory. In fact, Dianmu was the most rapidly intensified typhoon since 1960 in the northwestern Pacific (Pun et al. 2007). Within 18 hours (0000 UTC - 1800 UTC 15 June), it rapidly intensified from category 1 to the category 5 super-scale. This was more than three times the usual "rapid intensification" baseline of $30 \mathrm{kn}$ in 24 hours (Pun et al. 2007). As it progressed into the interior of the warm feature at 0600 UTC 16 June, Dianmu reached its peak intensity. This peak intensity was sustained for 12 hours until 1800 UTC 16 June and started to decline to the category 4 at 1800 UTC 17 June. Due to the lacked of upper ocean hydrological in situ data in the offshore Pacific, these intensity changes were not possible to be predicted in operational mode. The miss-predicted wind fields led to the miss-prediction of wave fields. During the passage of Dianmu, over-estimate of $2 \mathrm{~m}$ wave height was yielded by DNM. The MMM gave similar results $-2 \mathrm{~m}$ bias in wave height.

For the sake of understanding the effects of mis-predicted wind fields for the wave forecasts, comparisons of other typhoon cases, i.e., typhoons Aere, Songda and Haima are carried out. Comparisons between the observations to the 


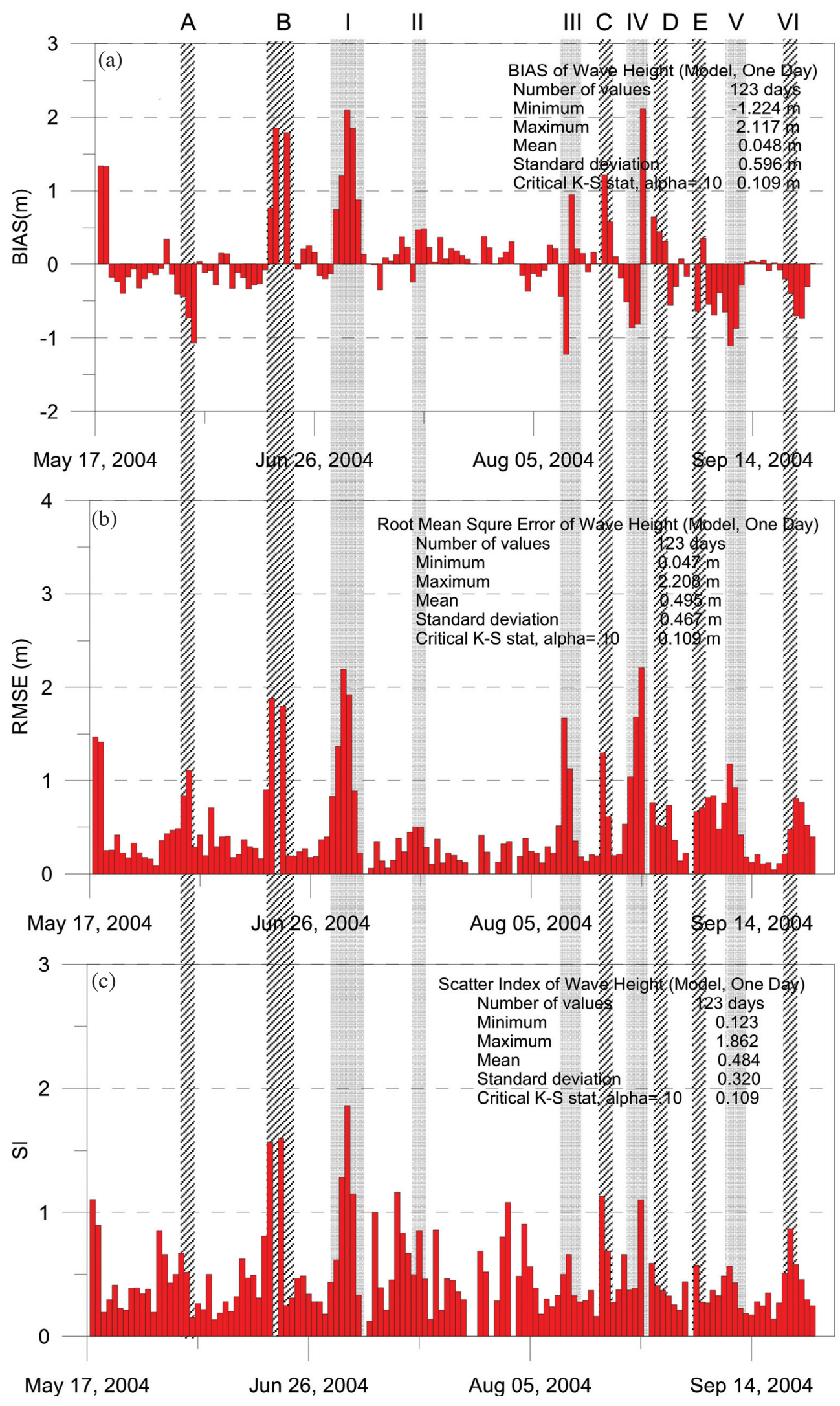

Fig. 8. Daily variation of the error indexes (a) BIAS, (b) RMSE, and (c) SI of the DNM wave height predictions (+1 day). The grey shaded areas indicate the typhoons, TD that were warned by CWB; the strip shaded areas indicate the far field typhoons which were not warned of by the CWB. The list of typhoons is in Table 1. 


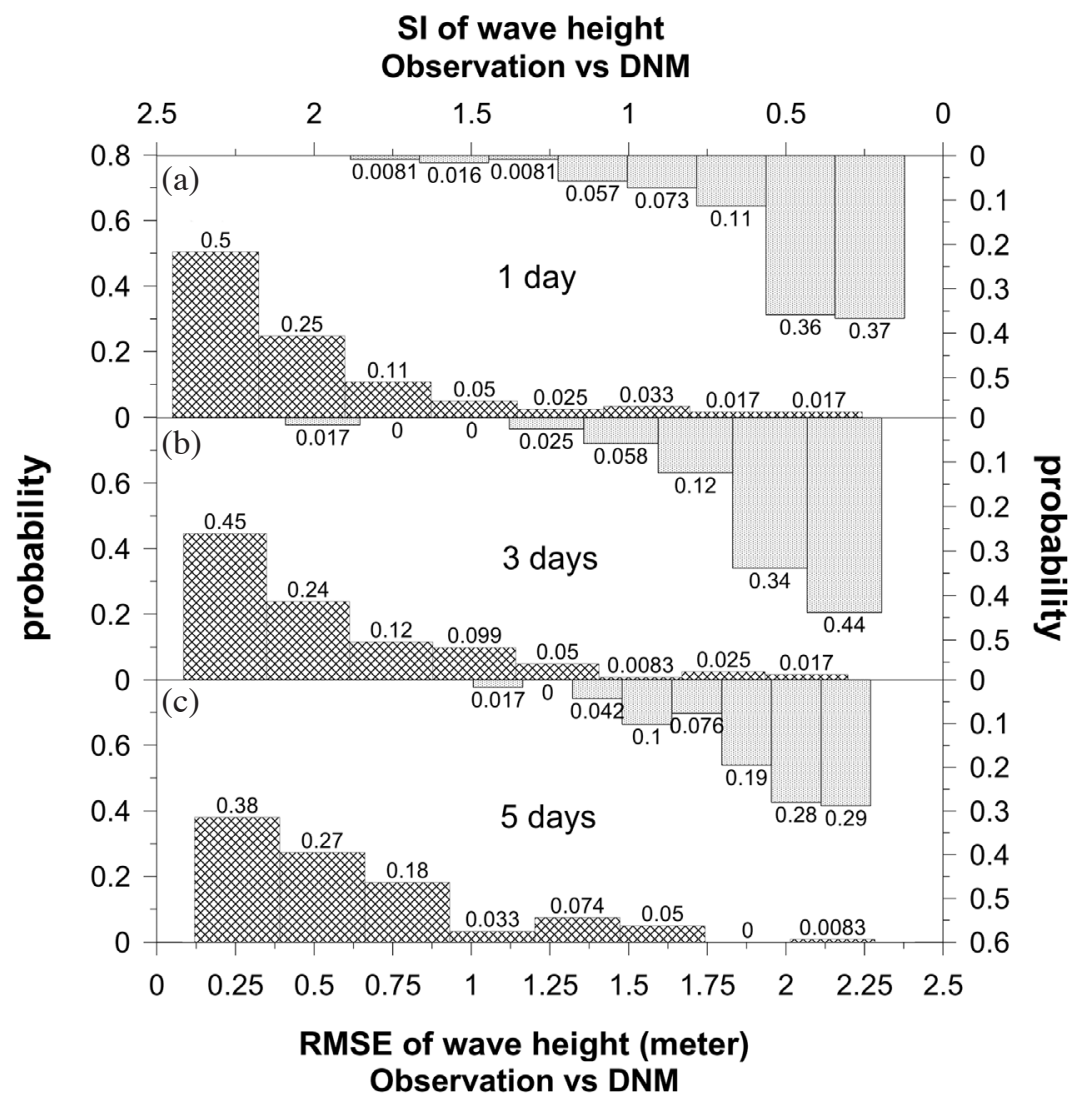

Fig. 9. Probability histograms of daily variance of error indexed RMSE and SI of DNM for (a) +1 day forecast, (b) +3 days forecast and (c) +5 days forecast.

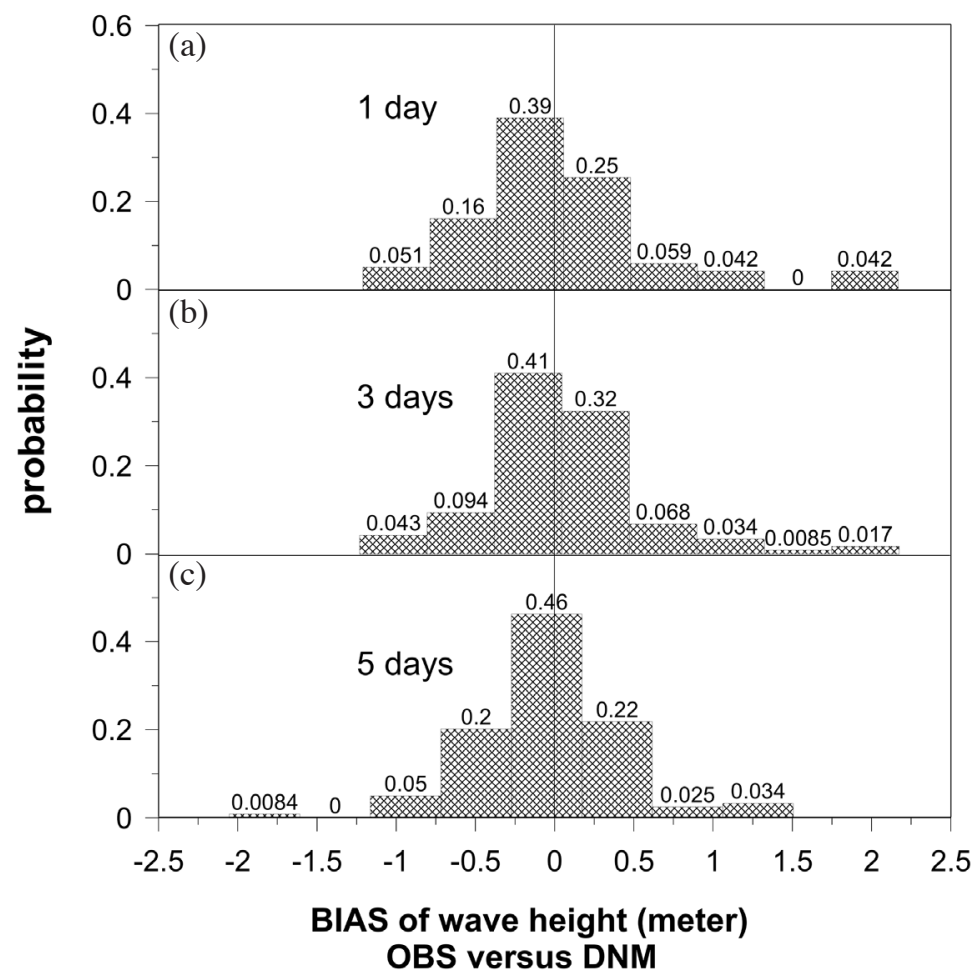

Fig. 10. Probability histograms of daily variance of error indexed BIAS of DNM for (a) +1 day forecast, (b) +3 days forecast, and (c) +5 days forecast. 


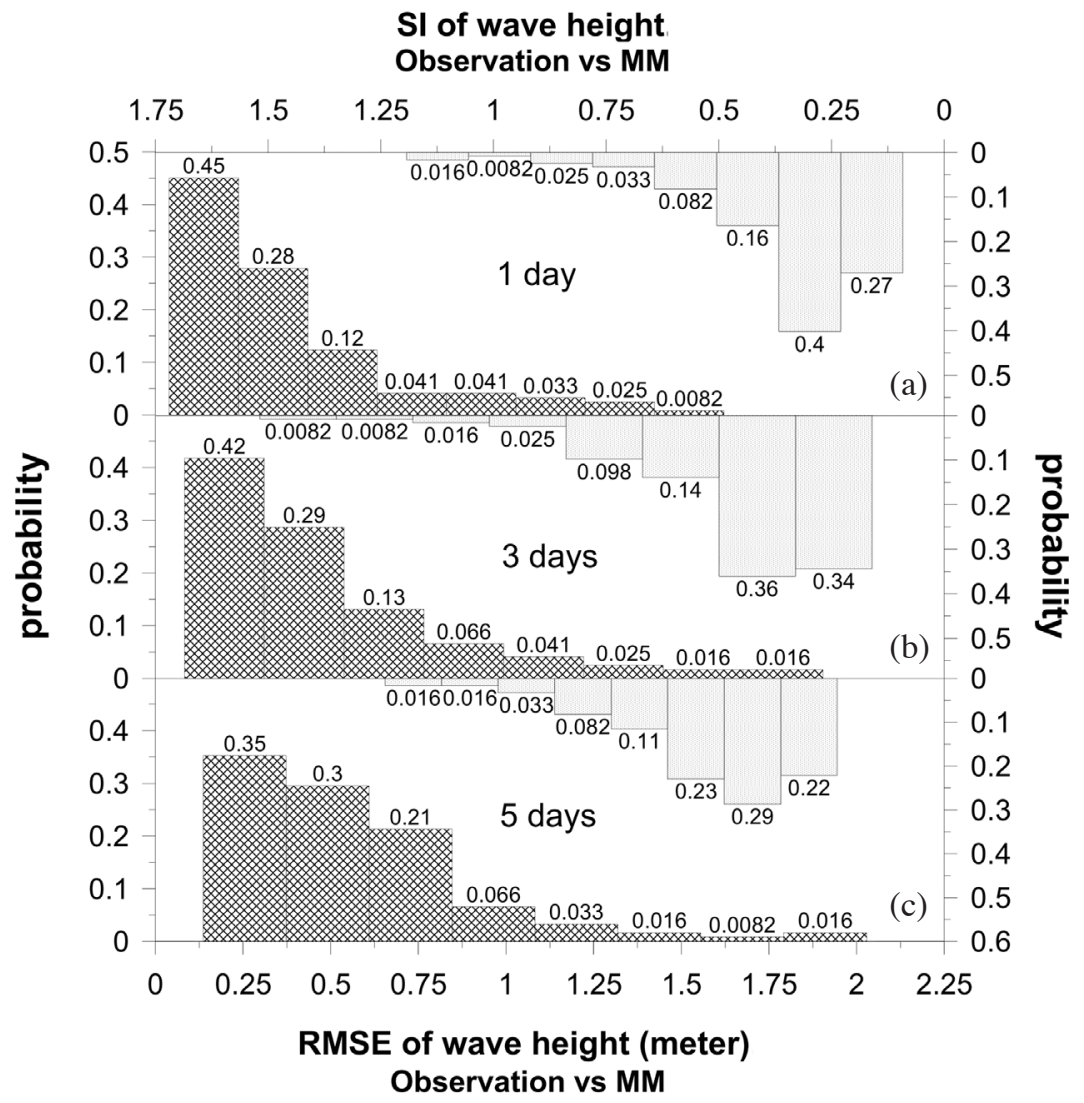

Fig. 11. Probability histograms of daily variance of error indexed RMSE and SI of MM for (a) +1 day forecast, (b) +3 days forecast, and (c) +5 days forecast.

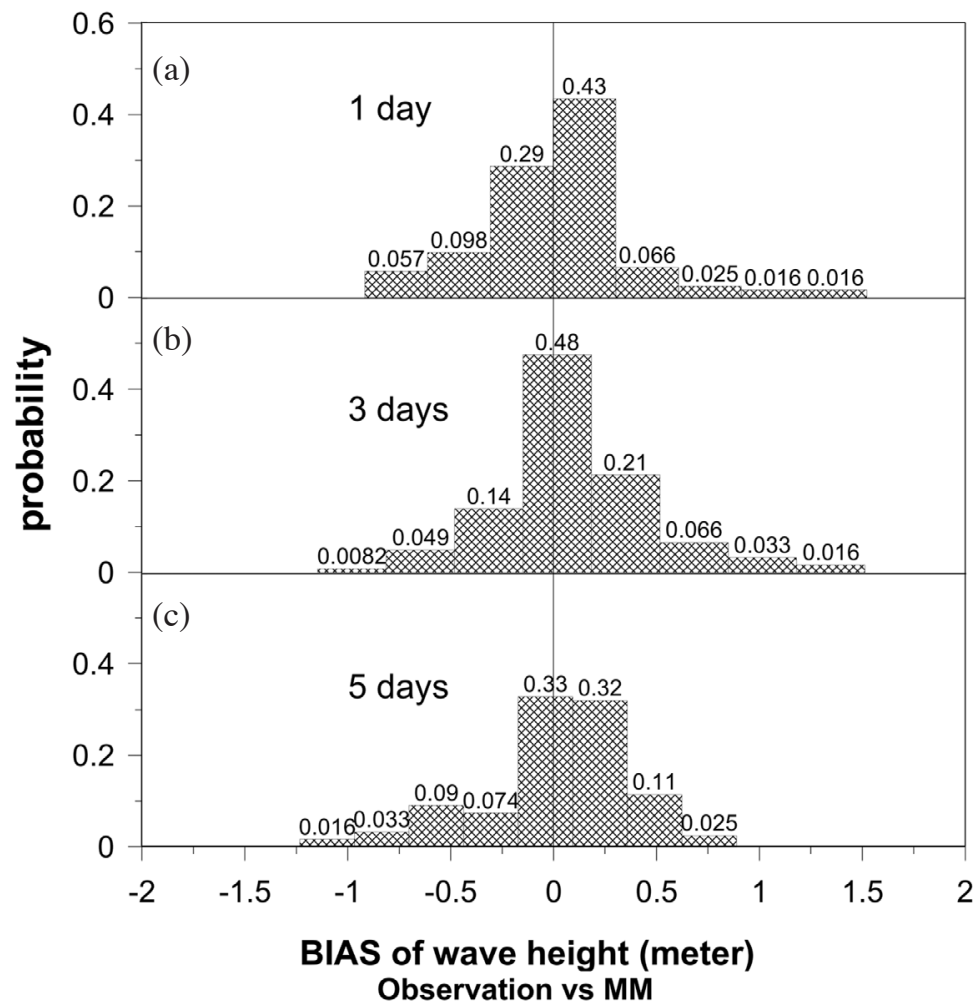

Fig. 12. Probability histograms of daily variance of error indexed BIAS of MM for (a) +1 day forecast, (b) +3 days forecast, and (c) +5 days forecast. 

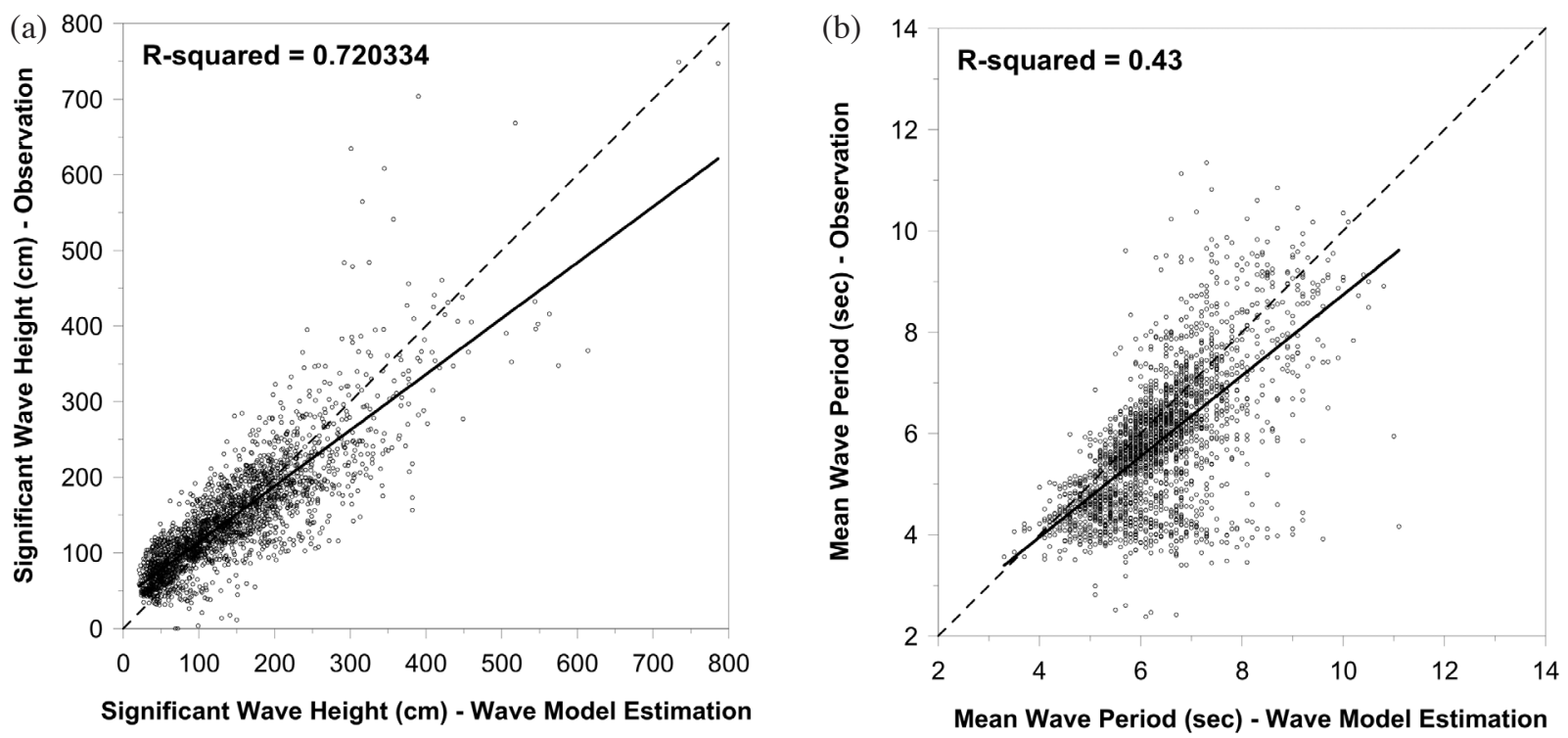

Fig. 13. Scatter plots of hourly +1 day wave forecast of MM for (a) Significant wave height; (b) Mean wave period.

Table 2. Error index of wave height prediction obtained from DMN.

\begin{tabular}{cccc}
\hline & BIAS (m) & RMSE (m) & SI \\
\hline +1 Day & $0.06 \mathrm{~m}$ & $0.485 \mathrm{~m}$ & 0.39 \\
+3 Days & $0.09 \mathrm{~m}$ & $0.537 \mathrm{~m}$ & 0.51 \\
+5 Days & $0.02 \mathrm{~m}$ & $0.596 \mathrm{~m}$ & 0.62 \\
\hline
\end{tabular}

Table 3. The error indexes of +3 days wave height prediction during Typhoon/Monsoon (DNM versus MM).

\begin{tabular}{|c|c|c|c|c|}
\hline \multicolumn{2}{|c|}{ Wave Height } & \multirow{2}{*}{$\begin{array}{c}\text { BIAS }(\mathbf{m}) \\
0.227\end{array}$} & \multirow{2}{*}{$\begin{array}{c}\text { RMSE (m) } \\
1.026\end{array}$} & \multirow{2}{*}{$\begin{array}{c}\text { SI } \\
0.562\end{array}$} \\
\hline & DNM & & & \\
\hline & MM & 0.105 & 0.749 & 0.425 \\
\hline \multirow{2}{*}{ Monsoon } & DNM & -0.011 & 0.511 & 0.648 \\
\hline & MM & 0.033 & 0.349 & 0.432 \\
\hline
\end{tabular}

Table 4 . The error indexes of +3 days wave periods during Typhoon/ Monsoon (DNM versus MM).

\begin{tabular}{c:cccc}
\hline \multicolumn{2}{c}{ Wave Period } & BIAS (sec) & RMSE (sec) & SI \\
\hline \multirow{3}{*}{ Typhoon } & DNM & -0.647 & 1.814 & 0.255 \\
& MM & 0.059 & 1.282 & 0.183 \\
\hdashline & DNM & -0.549 & 1.682 & 0.278 \\
\cline { 1 - 2 } Monsoon & MM & -0.147 & 0.842 & 0.126 \\
\hline
\end{tabular}

output of DNM and MM are illustrated in Fig. 14. The red dot denotes the observation, the blue cross denotes the MM output and the black triangle denotes the DNM. It should be noted that, both the atmospheric and wave model ran twice daily on $00 \mathrm{Z}$ and $12 \mathrm{Z}$ in operational mode. In each run, the forecast wind resulted from the atmospheric model was obtained 80 minutes after the $00 \mathrm{Z}$ and $12 \mathrm{Z}$, and thus was not able to drive the wave model in time. Therefore, the numerical wave model was fed and driven by the $+12 \mathrm{hr}$ forecasted wind fields to fulfill the request of forecasting issuance. For example, for the wave model run on $12 \mathrm{Z}$, it was fed by the output of atmospheric model resulted 12 hours ago from the $00 \mathrm{Z}$ run. It means that the latest wind fields, that had been corrected to be with less discrepancy, was not possible to be provided in time to the wave model to produce the latest wave forecasts. The errors of wind fields accumulated, led to mis-estimates of typhoon wave heights and periods. As shown in Fig. 14a of typhoon Aere, the forecasted wind fields were contaminated with more uncertainties. The +1 day forecasted track of typhoon center had a bias of about $90 \mathrm{~km}$, about $1 / 2$ of the radius at wind speed $14.2 \mathrm{~m} \mathrm{~s}^{-1}$ (Beaufort Scale 7), to the best track. This mis-predicted incurred the mis-estimation of wind directionality and wind speed on the wave fetch. In such case, wave will not be properly simulated and the in situ predictors could do very little to improve the accuracy of forecasts. It could be found that the predictions were even not capable to correct the trends.

Typhoon Haima and Songda, shown in Figs. 14b and c are another two cases. The predicted errors of the tracks of typhoon center in the +1 day forecasts were about 70 and $50 \mathrm{~km}$, respectively. If the predicted typhoon wind fields could accurately reflected the trajectory and intensity, the in situ predictor could then modify the output of the DNM. In 


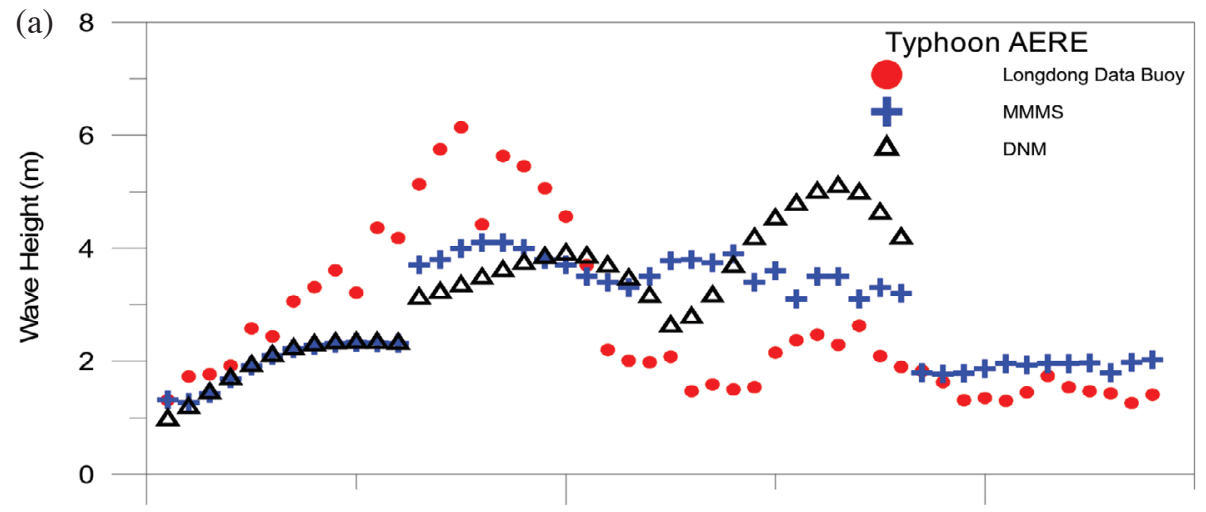

$\begin{array}{lll}\text { Aug 23: 8,2004 Aug 23: 18,2004 Aug 24: 4,2004 } & \text { Aug }\end{array}$

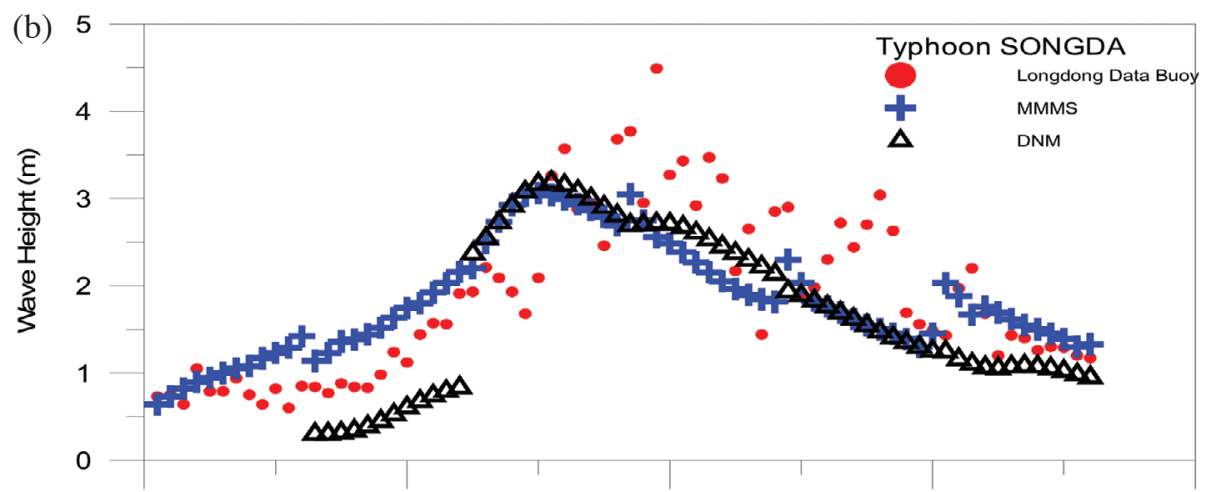

Sep 03: 8,2004 Sep 03: 18,2004 Sep 04: 4,2004 Sep 04: 14,2004 Sep 05: 0,2004

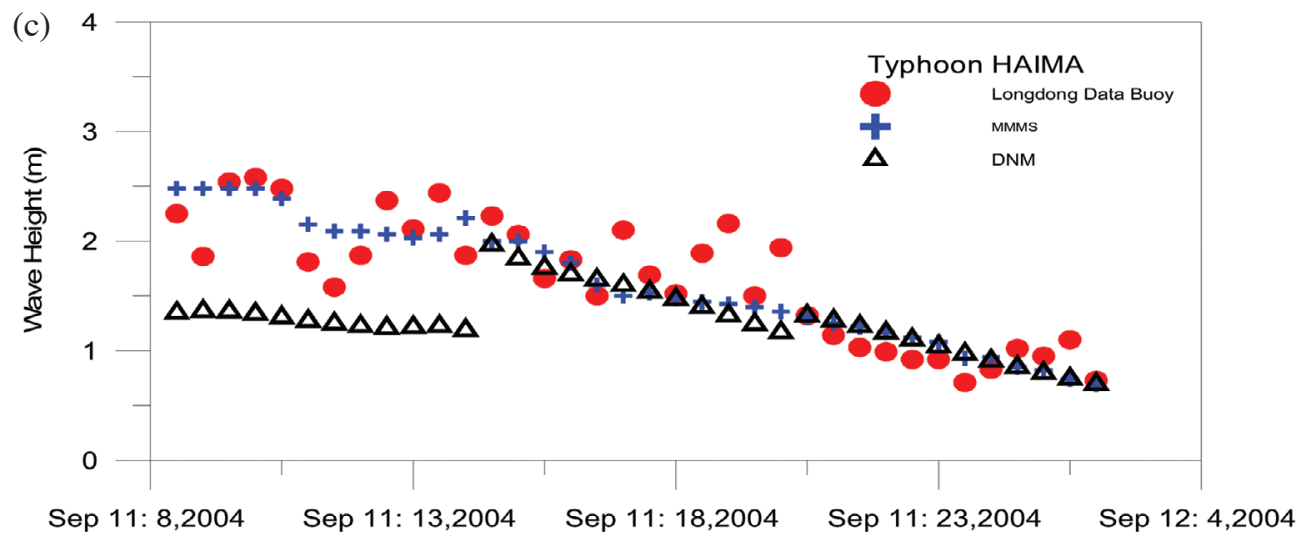

Fig. 14. Comparisons of numerical model ouput, in situ predictors modifications and observations of wave heights. (a) Typhoon Aere, (b) Typhoon Songda, and (c) Typhoon Haima.

Figs. $14 \mathrm{~b}$ and $\mathrm{c}$, it can be seen that the forecast error from MM gradually decreased. In other words, the quality of forecasted wind fields plays a key role to wave prediction. For +1 day predicted $10 \mathrm{~m}$ surface wind fields, if the bias of trajectory of the typhoon center exceeds $1 / 2$ of the radius of Beaufort Scale 7 wind speed of typhoon, the wave model results would not be valid. Based on the false predictions of waves, the in situ predictor's correction is only marginal.

Another very important phenomenon that affects maritime construction is the diurnal oscillation of wave heights and periods as illustrated in Fig. 15. If there are no dominat- ing weather systems in the vicinity of a construction site, due to the land-sea breeze, the sea state would be rather clam in the early morning and increased its severity in the afternoon (Neetu et al. 2006). The variation of the wave heights ranges from 0.5 to $2.0 \mathrm{~m}$ distributed in higher frequency bands. The land-sea breeze, which is a 3-dimensional meso-scale atmospheric circulation, is correlated to the gradient of airsea heat flux, mixing depth and the sea surface roughness (Wichink Kruit 2004). , It was not resolved in the CWB atmospheric model outputs. The fetch of sea breeze is in the range less than $110 \mathrm{~km}$ (Neetu et al. 2006), estimated 


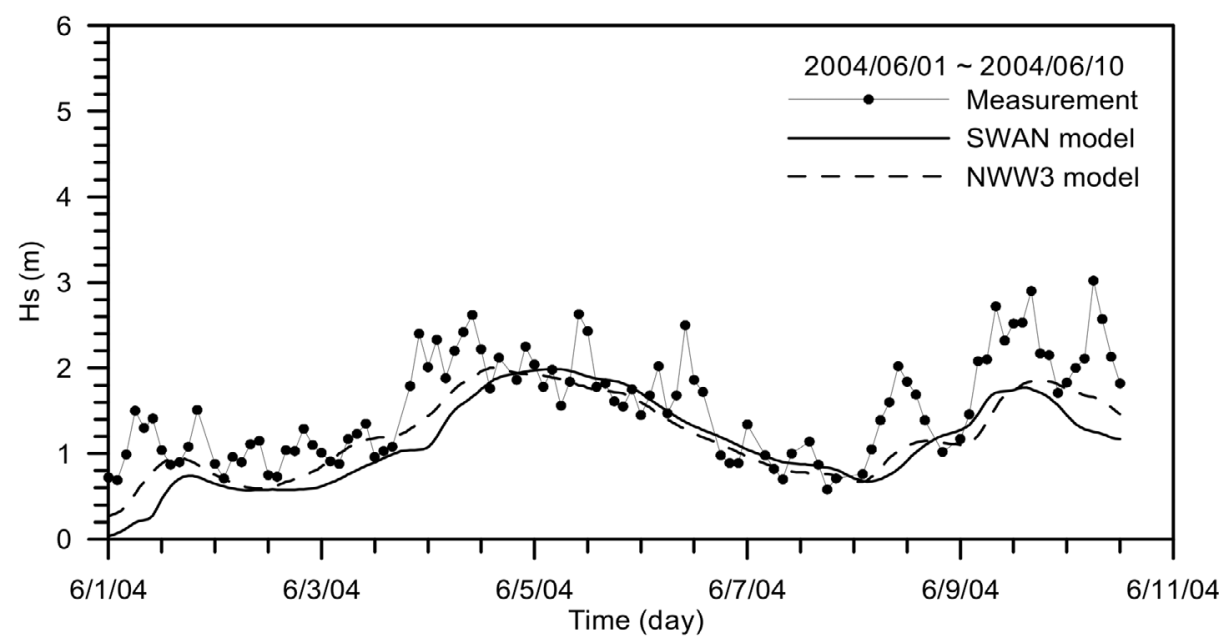

Fig. 15. An example of the diurnal oscillation of wave heights measured by the Longdong Buoy. Land and sea breezes induced diurnal wave heights oscillation ranges from $0.5 \sim 2.0 \mathrm{~m}$. The numerical model outputs for both SWAN and NWW3 smooth out the oscillation due to the fact that the maximum fetch is less than $100 \mathrm{~km}$, and it is difficult to be resolved in the predicted wind fields to drive the wave model.

from the measured wave spectral shape. Therefore, without this mechanism, which is the input to the wave model, wave height and period oscillation could not be reproduced. These phenomena were smoothed out in the wave predictions both from SWAN or NWW3 as illustrated in Fig. 15. Due to the relatively low wind speed of the sea breeze and limited fetch, the wave heights were limited, but they were crucial in present engineering applications. Considering the $1.5 \mathrm{~m}$ wave height threshold in the maritime engineering application, the diurnal wave height variation played a crucial role. The in situ predictors adopted the monitored the air-sea heat flux $Q_{H}$ and the temperature difference $\Delta T$ between the sea and land surface as the indicators to infer the strength of land-sea breeze. The amplitude of diurnal wave height oscillations were assumed to be linearly proportional to $\Delta T^{2} / Q_{H}$. The in situ predictors could enhance the performance by including diurnal wave height oscillations to the wave predictions. This is one of the major contributions from the in situ predictors in reducing the error from direct numerical model output.

\section{CONCLUDING REMARKS}

The Longmen regional wave forecast project has demonstrated the feasibility of implementation of an operational regional wave forecasting to the maritime engineering. The operational system consisted of a nested SWAN mode that, is flexible and able to respond to individual needs. For the establishment of regional wave prediction in the north east coast of Taiwan, two wave dissipation terms were reviewed, adopted and compared. The Alves and Banner (2003) formula of wave dissipation gave better results from the viewpoint of the error indexes of Bias, Root Mean Square Error and Scatter Index.
In contrast to the general operation centers, in the present forecasting system, a Mixed approach was applied, in which skilled marine meteorologists were placed as in situ predictors with guidance from various sources and directly modified the numerical model output. Based on the output of numerical model, the in situ predictors enhance the capability of the forecasting system through the following procedures: first, the trend of wave height and period evolution is modified according to the similar weather system patterns in the history and corresponding observed data, and second, tune the magnitude of wave heights and periods according to the real-time wave monitoring data and finally fine tune the results considering the land-sea breeze effects.

The quality of predicted wind fields, which are used to drive the wave model, is crucial to the performance of wave prediction. For +3 days wave predictions, about $20 \%$ of the uncertainties are due to forecasted wind fields. The In situ predictors do benefit the performance of the forecast system by about $30 \%$. This improvement was achieved by the corrections of typhoon wave prediction through the study of historical events. One should keep in mind that if the +1 day predicted wind fields (path of typhoon) obtained from atmospheric model deviates more than $1 / 2$ radius of the Beaufort scale 7 wind speed, then results from numerical model would be invalid and the in situ predictor's correction is marginal. Moreover, further improvement of the wave forecast is achieved by including the effects of diurnal wave height and period oscillations. This kind of diurnal oscillation is induced by the land/sea breeze and not able to be resolved in a numerical atmospheric model, but can be estimated by the temperature difference between sea/ land surface and the air-sea heat flux. The wave height and period oscillation occurs only in a local near shore region. Due to the weak wind speed of a sea breeze and limited 
fetch, the amplitude of the oscillation of the wave height ranged from 0.5 to $2.0 \mathrm{~m}$ and plays critical role for the maritime engineering applications due to the fact that the threshold of $1.5 \mathrm{~m}$ is just coincident to what the sea breeze would affect. As the local 3-D atmospheric circulation could not be resolved in the numerical models, an in situ predictor is considered to be necessary as well implementing numerical models in the field of maritime engineering applications.

Acknowledgements Authors gratefully thank Mr. MingYang Liao, the chief engineer at RSEA Engineering Corporation, for the assistance and the supports.

\section{REFERENCES}

Alves, J. H. G. M. and M. L. Banner, 2003: Performance of a saturation-based dissipation-rate source term in modelling the fetch-limited evolution of wind waves. J. Phys. Oceanogr., 33, 1274-1298, doi: 10.1175/1520 $-0485(2003) 033<1274:$ POASDS $>2.0 . C O ; 2$. [Link]

Banner, M. L., A. V. Babanin, and I. R. Young, 2000: Breaking probability for dominant waves on the sea surface. J. Phys. Oceanogr., 30, 3145-3160, doi: 10.1175/15200485(2000)030<3145:BPFDWO >2.0.CO;2. [Link]

Banner, M. L., J. R. Gemmrich, and D. M. Farmer, 2002: Multiscale measurements of ocean wave breaking probability. J. Phys. Oceanogr., 32, 3364-3375, doi: 10.1175/1520-0485(2002)032<3364:MMOOWB>2.0. CO;2. [Link]

Booij, N., L. H. Holthuijsen, and R. C. Ris, 1996: The SWAN wave model for shallow water. Proc. $25^{\text {th }}$ Int. Conf. Coastal Eng., 668-676.

Cox, A. T. and V. J. Cardone, 2002: 20 Years of operational forecasting at ocean weather. Proc. $7^{\text {th }}$ International Workshop on Wave Hindcasting and Forecasting, Banff, Alberta, Canada, 21-25.

Donelan, M. and Y. Yuan, 1994: Wave dissipation by surface processes. In: Komen, G. J., L. Cavaleri, M. Donelan, K. Hasselmann, S. Hasselmann, and P. A. E. M. Janssen (Eds.), Dynamics and Modelling of Ocean Waves, Cambridge Univ. Press, 143-155, doi: 10.2277/0521577810. [Link]

Holthuijsen, L. H., N. Booij, R. C. Ris, J. H. Andorka, and J. C. M. Jong, 1997: A verification of the thirdgeneration wave model SWAN along the southern North Sea coast. Proc. 3rd International Symposium on Ocean Wave Measurement and Analysis, WAVES' 97, ASCE, 49-63.

Holthuijsen, L. H., N. Booij, R. C. Ris, I. J. G. Haagsma, A. T. M. M. Kieftenburg, and R. Padilla-Hernandes,
1999: SWAN User Manual, Delft University of Technology press.

Janssen, P. A. E. M., 1989: Wave induced stress and the drag of air flow over sea waves. J. Phys. Oceanogr., 19, 745-754, doi: 10.1175/1520-0485(1989)019<0745: WISATD>2.0.CO;2. [Link]

Janssen, P. A. E. M., 1991: Quasi-linear theory of wind-wave generation applied to wave forecasting. J. Phys. Oceanogr., 21,1631-1642, doi: 10.1175/1520-0485(1991)021 $<1631$ :QLTOWW>2.0.CO;2. [Link]

Komen, G. J., S. Hasselmann, and K. Hasselmann, 1984: On the existence of a fully developed wind-sea spectrum. J. Phys. Oceanogr., 14, 1271-1285, doi: 10.1175/15200485(1984)014<1271:OTEOAF>2.0.CO;2. [Link]

Liou, C. S., J. H. Chen, C. T. Terng, F. K. Wang, C. T. Fong, T. E. Rosmod, H. C. Kuo, C. H. Shiao, and M. D. Cheng, 1997: The second generation global forecast system at the central weather bureau in Taiwan. Weather Forecast., 12, 653-663, doi: 10.1175/1520-0434(1997) 012<0653:TSGGFS $>2.0 . C O ; 2$. [Link]

Liu, P. C. and A. V. Babanin, 2004: Using wavelet spectrum analysis to resolve breaking events in the wind wave time series. Ann. Geophys., 22, 3335-3345.

Neetu, S., S. Shetye, and P. Chandramohan, 2006: Impact of sea breeze on wind-seas off Goa, west coast of India. J. Earth Syst. Sci., 115, 229-234, doi: 10.1007/BF027 02036. [Link]

Pun, I. F, I. I. Lin, C. R. Wu, D. S. Ko, and W. T. Liu, 2007: Validation and application of altimetry-derived upper ocean thermal structure in the western north $\mathrm{Pa}$ cific ocean for typhoon-intensity forecast. IEEE Trans. Geosci. Remote Sensing, 45, 1616-1630, doi: 10.1109/ TGRS.2007.895950. [Link]

Rogers, W. E., P. A. Huang, and D. W. Wang, 2003: Investigation of wave growth and decay in the SWAN model: Three regional-scale applications. J. Phys. Oceanogr., 33, 366-389, doi: 10.1175/1520-0485(2003)033<0366: IOWGAD>2.0.CO;2. [Link]

Van der Westhuysen, A. J., M. Zijlema, and J. A. Batthes, 2007: Nonlinear saturation-based whitecapping dissipation in SWAN for deep and shallow water. Coast. Eng., 54, 151-170, doi: 10.1016/j.coastaleng.2006. 08.006. [Link]

Wichink Kruit, R. J., A. A. M. Holtsalg, and A. B. C. Tijm, 2004: Scaling of the sea-breeze strength with observations in the Netherlands. Bound.-Layer Meteor., 112, 369-380.

Young, I. R. and A. V. Babanin, 2006: Spectral distribution of energy dissipation of wind-generated waves due to dominant wave breaking. J. Phys. Oceanogr. 36, 376394, doi: 10.1175/JPO2859.1. [Link] 